\title{
An Evaluation of Adding a Low-cost Temperature String to NDBC Weather Buoys for Monitoring Heat Content in the Caribbean Sea
}

\author{
Karen R. Grissom amd Lex LeBlanc \\ NOAA, National Data Buoy Center \\ Stennis Space Center, MS
}

\begin{abstract}
In 2005, the National Data Buoy Center (NDBC) Weather Buoy network was expanded with 15 additional buoys in the Caribbean Sea in support of early detection and improved forecasts of Atlantic Hurricanes. These buoys have now become a standard and highly valuable asset to the Weather Buoy network, and as such, some will be upgraded with the modular Self Contained Ocean Observing Payload (SCOOP) to add new capabilities and value. One of these new capabilities includes real-time observations of subsurface temperature and salinity measurements. With this new ability, the enhanced Weather Buoys located in "hurricane alley" will be better positioned to support the real-time analyses of ocean heat content and high frequency weather phenomena linked to hurricanes. As part of this effort, NDBC assessed the utility of adding a low-cost thermistor string in lieu of traditional oceanographic sensors and deployed two SCOOP stations $13 \mathrm{~km}$ apart in the Caribbean Sea at Weather Buoy station 42058. One station was equipped with standard oceanographic sensors used as a reference, while the other station was equipped with a thermistor string. The purpose of the field test was verify the thermistor string observations meet NDBC accuracy requirements and to evaluate the ease of operation and durability within the field environment. The results indicate the thermistor string is acceptable within $\pm 0.1^{\circ} \mathrm{C}$ greater than $80 \%$ of the time in the upper layer, yet when using the observations to calculate ocean heat content, there is an average error of $11 \%$, Lastly, our results show the sensor response time, ease of deployment and durability of the thermistor string are not suitable for hurricane observations.
\end{abstract}

\section{INTRODUCTION}

The Weather Buoy network is a collection of 106 surface moorings located on the coastal and offshore waters of the continental U.S., Alaska and Hawaii operated by NOAA's National Data Buoy Center (NDBC). The mission of the network is to collect real-time marine meteorology and oceanographic observations in support of NOAA, National Weather Service forecasts. Until recently, this network was heavily focused on measurements of surface meteorology (wind speed and direction, barometric pressure, air temperature, and relative humidity) with oceanographic measurements limited to waves and a thru-hull sea-surface water temperature. Last year, only one Weather Buoy collected salinity data and none subsurface water temperature. However, in June 2013, NDBC was allocated funding in a Sandy Supplemental Appropriation to recapitalize offshore buoys in the Atlantic, Caribbean and Gulf of Mexico and to improve ocean observations for hurricane forecasting.

Using Sandy Supplemental Appropriation, NDBC developed a new modular data acquisition system. The new system, known as SCOOP (Self-Contained Ocean Observation Payload) was designed to expand NDBC's present measurement capabilities, while decreasing latency of the measurements. The concept was to design and build a modular observing system of lower cost than the existing $3 \mathrm{~m}$ buoy that was easy to assemble in the field, mount to rather than be integrated into a buoy hull, and use modern meteorological, oceanographic and directional waves sensors. In addition, the new SCOOP added cameras, AIS, and a subsurface ocean temperature profile capability to measure ocean heat content (OHC).

For several decades, research has been investigating the importance of ocean heat content and tropical cyclone intensity [1 and 2]. Previous research has shown a weak correlation between sea-surface temperature and storm intensity, this is attributed to satellite-derived skin temperature that does not accurately depict subsurface thermal conditions [3]. However, some studies [4 and 5] indicate a link between reduced sea-surface temperature cooling of the inner-core and intensification due to large surface fluxes, showing that a modest change can dramatically alter air-sea heat fluxes. Recently, the inclusion of $\mathrm{OHC}$ in the National Hurricane Center SHIPS model has been shown to significantly reduce the error of category 5 hurricane forecasts [5].

This paper reports the results of an operational field test comparing temperature data collected on two of the new SCOOP systems, one equipped with standard oceanographic instruments and the other with a low-cost thermistor string. The purpose of the inter-comparison was to verify the thermistor string temperature measurements meet or exceed the reported accuracy of NDBC requirements, to assess its usefulness for measuring $\mathrm{OHC}$, and to evaluate the operational performance of the thermistor string compared to standard NDBC instruments.

\section{OPERATIONAL FIELD TEST}

\section{A. Deployment Description}

The field test was located at NDBC station 42058 in the central Caribbean Sea, approximately $200 \mathrm{~nm}$ southeast of Jamaica. Since NDBC does not currently collect subsurface temperature data on Weather Buoys, two SCOOP buoys were deployed to evaluate performance, one equipped with standard oceanographic sensors used as a reference, and the other with the thermistor string. The test data were collected from 30 May to 28 June, 2015 when the thermistor string stopped 
transmitting data. However, both SCOOP buoys continued to transmit surface meteorological observations until 21 May, 2016 when the reference buoy was recovered. High sea conditions prohibited recovery of the SCOOP buoy equipped with the thermistor string so the actual cause of the failure cannot be confirmed until the next maintenance visit, scheduled for spring 2017.

Fig. 1 shows the deployment location of the three moorings, two SCOOP buoys and the NDBC operational Weather Buoy station. The two test buoys were deployed approximately $13 \mathrm{~km}$ apart and $10 \mathrm{~km}$ north of station 42058 in the Colombian Basin and west of the Beata Ridge in water depth of approximately 4140 meters. At this location, the buoys were located along the northern perimeter of the Caribbean Current, which is an extension of the westward flowing North Equatorial Current. The core velocities of the Caribbean Current are known to reach $0.6 \mathrm{~m} / \mathrm{s}$ in the upper 100 meters after moving through the Aruba Gap and have a weaker $(\sim 0.4 \mathrm{~m} / \mathrm{s})$ eastward moving underflow, the PanamaColombia countercurrent centered at 200 meters [6].

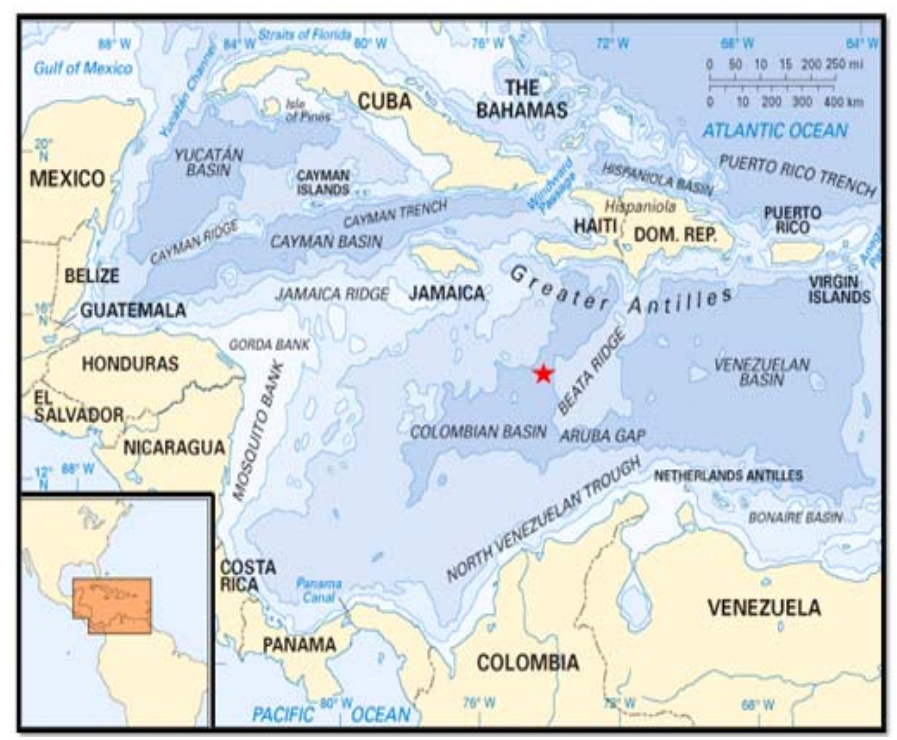

Fig. 1. Bathymetry map showing the location of the NDBC SCOOP operational test site in the Caribbean Sea.

\section{B. System Configuration Description}

The northernmost SCOOP buoy (42S58) was deployed as an ocean observation reference system for the operational field test. This buoy was equipped with the high accuracy $( \pm 0.002$ ${ }^{\circ} \mathrm{C}$ ) inductive instruments from Sea-Bird Electronics (SBE) currently used by NDBC for climate-quality observations. In contrast, the southern SCOOP buoy (42T58) was equipped with the experimental low-cost thermistor line with a stated accuracy of $0.07{ }^{\circ} \mathrm{C}$. The mooring diagram in Fig. 2 illustrates the differences between these two buoys systems.

Station 42S58 sea surface temperature used the SBE 37SM serial conductivity temperature (CT) sensor installed at the $1 \mathrm{~m}$ depth on the buoy bridle. The subsurface instruments consisted of a combination of nine inductive SBE sensors deployed on an IM (jacketed wire) line. The inductive sensors were a mix of three SBE-39 temperature sensors, three SBE39 temperature and pressure sensors, and three SBE-37 conductivity, temperature and pressure sensors. The Met Module included the Vaisala all-in-one and the extended range Met package. This system was configured similar to a standard TAO station with each subsurface temperature sensor programmed to automatically collect data every 10 minutes and the payload polling the data from each sensor once per hour.

Station 42 T58 was also configured with the SBE 37-SM CT sensor installed on the bridle. The subsurface temperature data was measured with the RST Instruments ThermArray TH0100 thermistor string with nine embedded temperature probes corresponding to the depths shown in Fig. 2. The thermistor line was deployed by attaching it to a 150 meter IM line. The Met Module included the Gill all-in-one sensor and the extended range MET package. The thermistor string collected a sample when it received a poll command from the SCOOP payload once every 10 minutes. An RS-485 to RS232 sensor interface was installed in the SCOOP Ocean Module to communicate with the thermistor line.

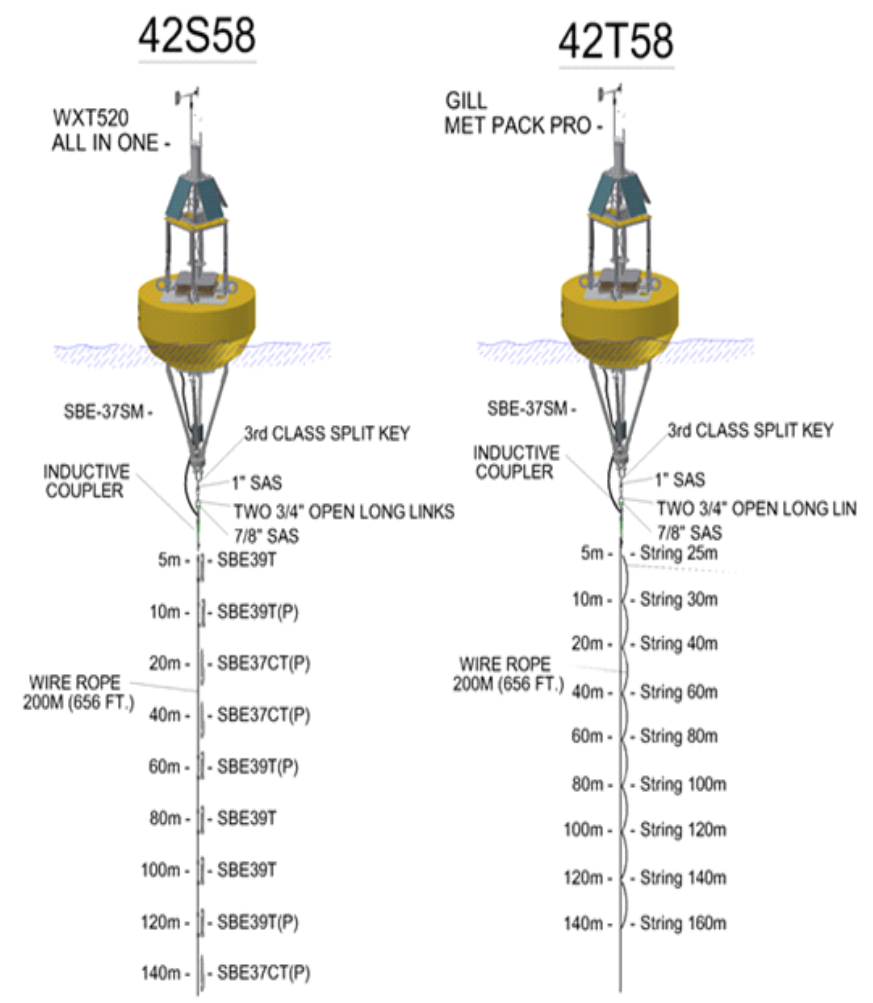

Fig. 2. Partial mooring diagram showing the configuration of subsurface temperature sensors for the two SCOOP buoys deployed at NDBC station 42058. 


\section{RESULtS}

\section{A. Engineering Evaluation}

The NDBC engineering evaluation used several criteria to assess the performance of the thermistor line for obtaining measurements of temperature at depth, these included accuracy of sensor specification, sensor response time, method of deployment, and survivability in a marine environment.

Prior to deployment the sensor specification was tested at the NDBC ocean lab. A 110 meter thermistor string was compared to a Hart Scientific Precision Temperature bath. The tests were performed by placing the spooled thermistor string spool in the bath and recording the resistance output of the five sensors at temperatures ranging from $2^{\circ} \mathrm{C}$ to $35^{\circ} \mathrm{C}$. The results showed the thermistor line accuracy of $0.05{ }^{\circ} \mathrm{C}$ was higher than the manufacturer specification at the lower temperatures, but deteriorated to approximately $0.2^{\circ} \mathrm{C}$ at $35^{\circ} \mathrm{C}$.

A test of sensor response time was performed on thermistor string fifth sensing element (PT5) to determine the latency to changes in temperature. The thermistor line was allowed to stabilize in air overnight and then placed in a $10^{\circ} \mathrm{C}$ temperature bath where PT5 data were collected once per second. The test showed the response time to be slow, to reach within one degree of the bath temperature the thermistor line took 5.3 minutes and to stabilize within the stated accuracy of $0.07^{\circ} \mathrm{C}$ took 8.7 minutes (Fig. 3). During the response time test, the bath temperature was relatively stable with a $0.16^{\circ} \mathrm{C}$ increase.

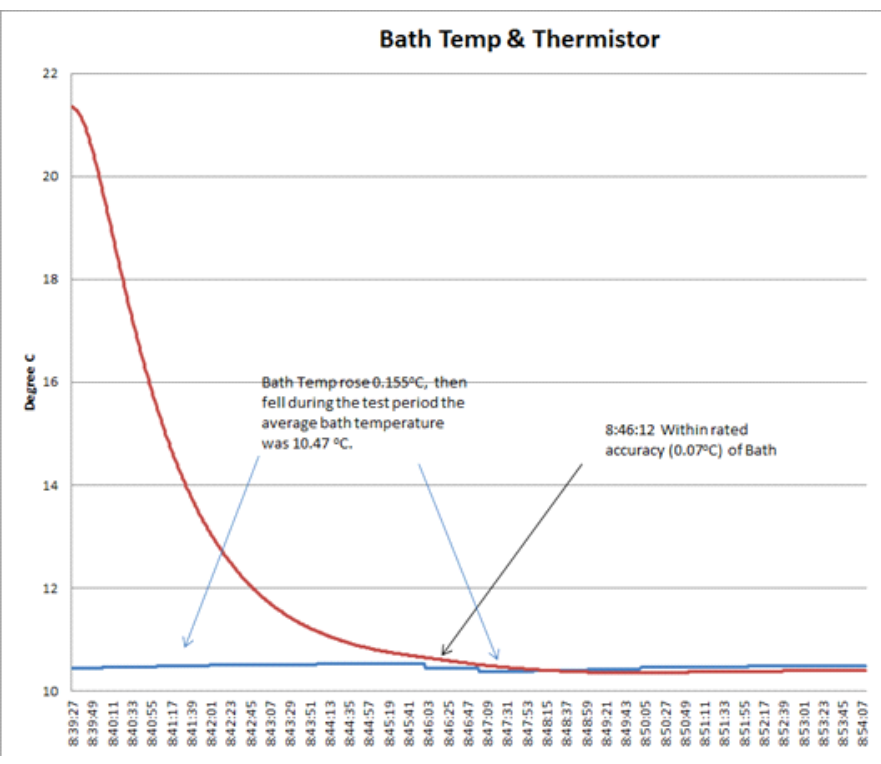

Fig. 3. Thermistor string (red) response time test in Hart Scientific bath (blue) showing an 8.7 minute lag to reach specified accuracy.
To determine the best method of deployment NDBC conducted a handling test of the thermistor string at the NDBC Stennis Space Center facilities. The thermistor line was attached to the IM line and the two were spooled lunspooled and wrapped on a capstan causing the thermistor line to break with little tension. To prevent a similar failure at deployment it was decided the thermistor string needs to be attached to the IM line as the IM line is being payed out with sufficient slack between probes (Fig. 2) to prevent transferring the mooring load forces from the IM line to the thermistor string.

This method of deployment, while effective for minimizing the tension contributed to a deployment depth error. A pre-marked IM line was used as a deployment template for aligning the thermistor string sensing elements to the selected observation depths. During the deployment, the field technicians were not able to match all of the thermistor's sensing probes with the specific depths marks. This resulted in deployment depth errors that increased down the IM line, estimated by the technicians to be 3-5 meters shallow of the predefined mark at the $140 \mathrm{~m}$ depth.

The thermistor string failed 30 days after deployment on 29 June, 2015. However, given the proximity to the Caribbean Current and the strong wind speeds (mean $10.7 \mathrm{~m} / \mathrm{s}$ ), the longevity could increase in a more benign environment. The pressure sensors installed on the IM line of buoy $42 \mathrm{~S} 58$ frequently exhibited vertical excursions in excess of $10 \%$ of the deployment depth indicating strong currents and tension on the thermistor line.

\section{B. Data Evaluation}

The dataset analyzed consisted of 4320 observations of water temperature measurements collected at both stations along with pressure and conductivity from station 42S58. To assess the impact of different environmental conditions on the inter-comparison, the sea-surface temperature (SST) was measured at each station with a common instrument, the SBE 37-SM CT sensor. The results of the SST inter-comparison are shown in Fig. 4. The temperature difference curve in this figure demonstrates that if we use the Weather Buoy SST accuracy requirements of $\pm 1^{\circ} \mathrm{C}$ all data are within the tolerance limits. However, given the narrow SST range $(<$ $1.5^{\circ} \mathrm{C}$ ) at each station, typical of open ocean tropical water [7 and 8], a higher accuracy requirement is needed to resolve diurnal variations. At an accuracy of $\pm 0.1^{\circ} \mathrm{C}$ there was agreement between almost $82 \%$ SST observations, and at the maximum difference of $\pm 0.53^{\circ} \mathrm{C}$ almost $95 \%$ of the SST data agreed. However, at the accuracy of $\pm 0.01^{\circ} \mathrm{C}$ used for climate observations, only $21 \%$ of the SST data agreed.

The high agreement $\left(\mathrm{R}^{2}=0.84\right)$ between SST observations supports a homogenous surface environment, the mean SST difference was $0.04^{\circ} \mathrm{C} \pm 0.09$, and is further supported by the nearly identical wind speed (mean difference $-0.1 \pm 0.6 \mathrm{~m} / \mathrm{s}$ ) and barometric data (mean difference $0.3 \pm 0.08 \mathrm{mb}$ ). The deployment spanned a limited range of environmental conditions with winds speeds ranging from $5-15 \mathrm{~m} / \mathrm{s}$ and atmospheric pressure ranging from 1009-1015 mbar. 


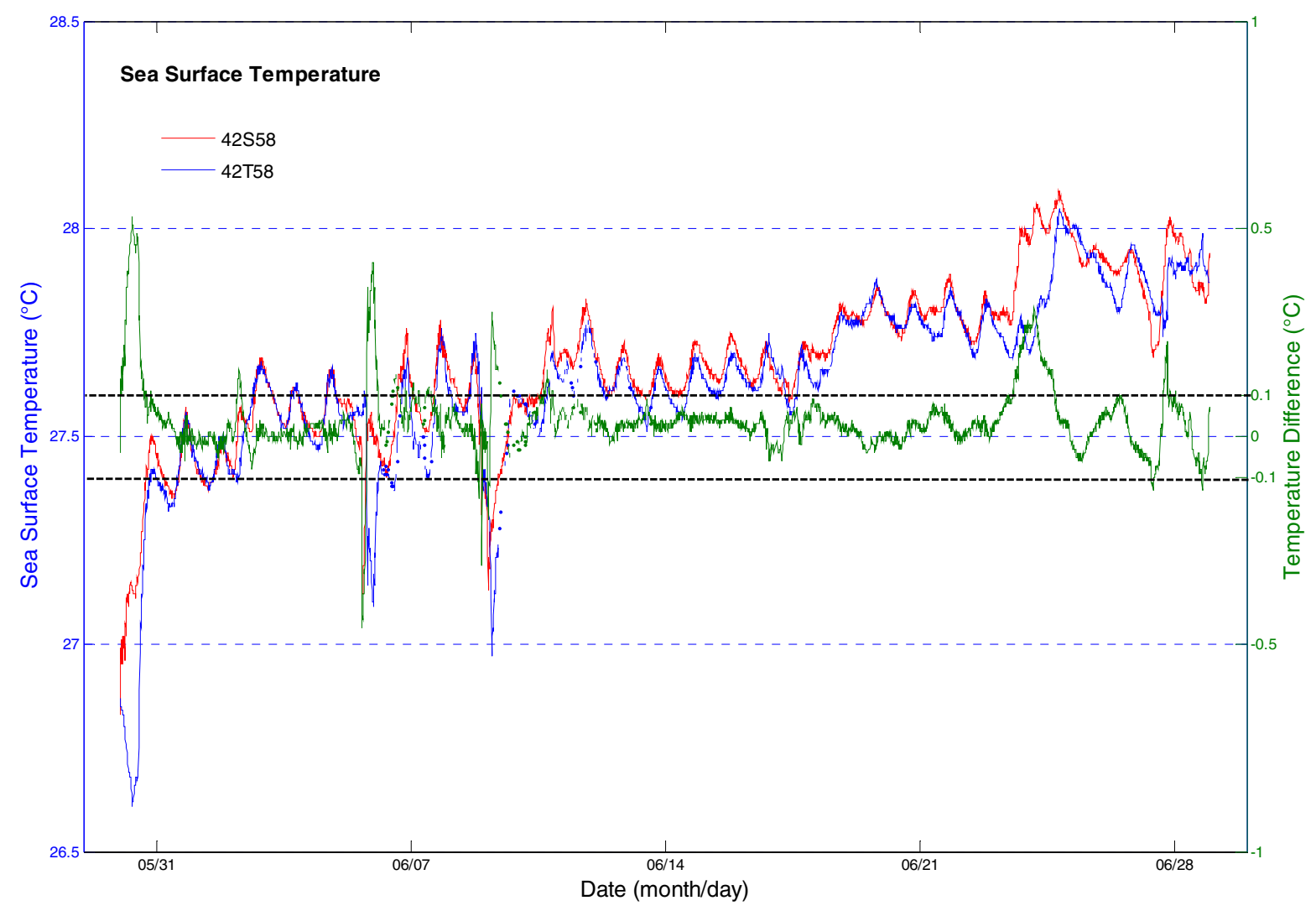

Fig. 4 Comparison of sea-surface temperature collected at station 42S58 (red) to $42 \mathrm{~T} 58$ (blue) and the temperature difference (green) between stations.

The time series comparing the subsurface temperature measurements at each station are shown in Fig. 5. The subsurface temperature during this period had a range of $3.63^{\circ} \mathrm{C}$, with a maximum value of $28.09{ }^{\circ} \mathrm{C}$ at $5 \mathrm{~m}$ to a minimum of $24.46^{\circ} \mathrm{C}$ at $140 \mathrm{~m}$. The general pattern was one of increasing stratification with depth. There was a constant nearly isothermal mixed surface layer extending down to 20 meters, and to 80 meters during the period between June 1320 when the wind speed increased to greater than $10 \mathrm{~m} / \mathrm{s}$ and shifted from SE to NE. This temporary deepening of the mixed layer was reflected in the water temperature differences between the two stations (Fig. 6). During this time, the mean absolute difference at $80 \mathrm{~m}$ decreased from $0.14^{\circ} \mathrm{C}$ to $0.03^{\circ} \mathrm{C}$ comparable to the upper $(<20 \mathrm{~m})$ layer mixed difference of $<0.05^{\circ} \mathrm{C}$. This pattern not only reflects the wind influencing the depth of the mixed layer, but the core of the Caribbean Current as discussed above with an increasing difference between the stations at depth.

The distribution of temperature to $20 \mathrm{~m}$ was of a wellmixed surface layer with approximately $87 \%$ of observations found between a narrow $0.5^{\circ} \mathrm{C}$ band, from 27.4 to $27.9^{\circ} \mathrm{C}$. Whereas, at $80 \mathrm{~m}$ the temperature distribution represents a transition zone between the well-mixed surface and the top of the thermocline. At this depth only $67 \%$ and $69 \%$ of the observations are found within the narrow surface layer temperature band. The distribution at $140 \mathrm{~m}$ showed a wider spread with $88 \%$ and $93 \%$ of data found between $25.6-27.0^{\circ} \mathrm{C}$. Comparing the two stations we note both are negatively skewed, indicating an asymmetric distribution. However, at all depths except 80 meters, the thermistor string skewness was almost twice that of the inductive instruments, indicating more spread to the left of the sample mean at this station than station 42S58 and an underestimation of the temperature relative to the reference instruments.

A summary of the performance measurements are given in Table 1. The mean difference at each depth shows a change from the thermistor string measuring lower temperatures in the upper layer to higher temperature at depth. This depth dependence change in the performance is also reflected in the other performance metrics, such as percent agreement, standard deviation of mean, mean absolute error (MAE), and the correlation coefficient. The MAE shows an acceptable error $\left(< \pm 0.1^{\circ} \mathrm{C}\right)$ for the upper layer, $80 \mathrm{~m}$, but increases with depth to more than twice the stated accuracy of the thermistor string. As seen in the increasing stratification with depth (Fig. 5 and 6) the larger error below 80 could be the result of different subsurface environmental condition between the stations, in particular, the influence of the Caribbean Current [9]. 

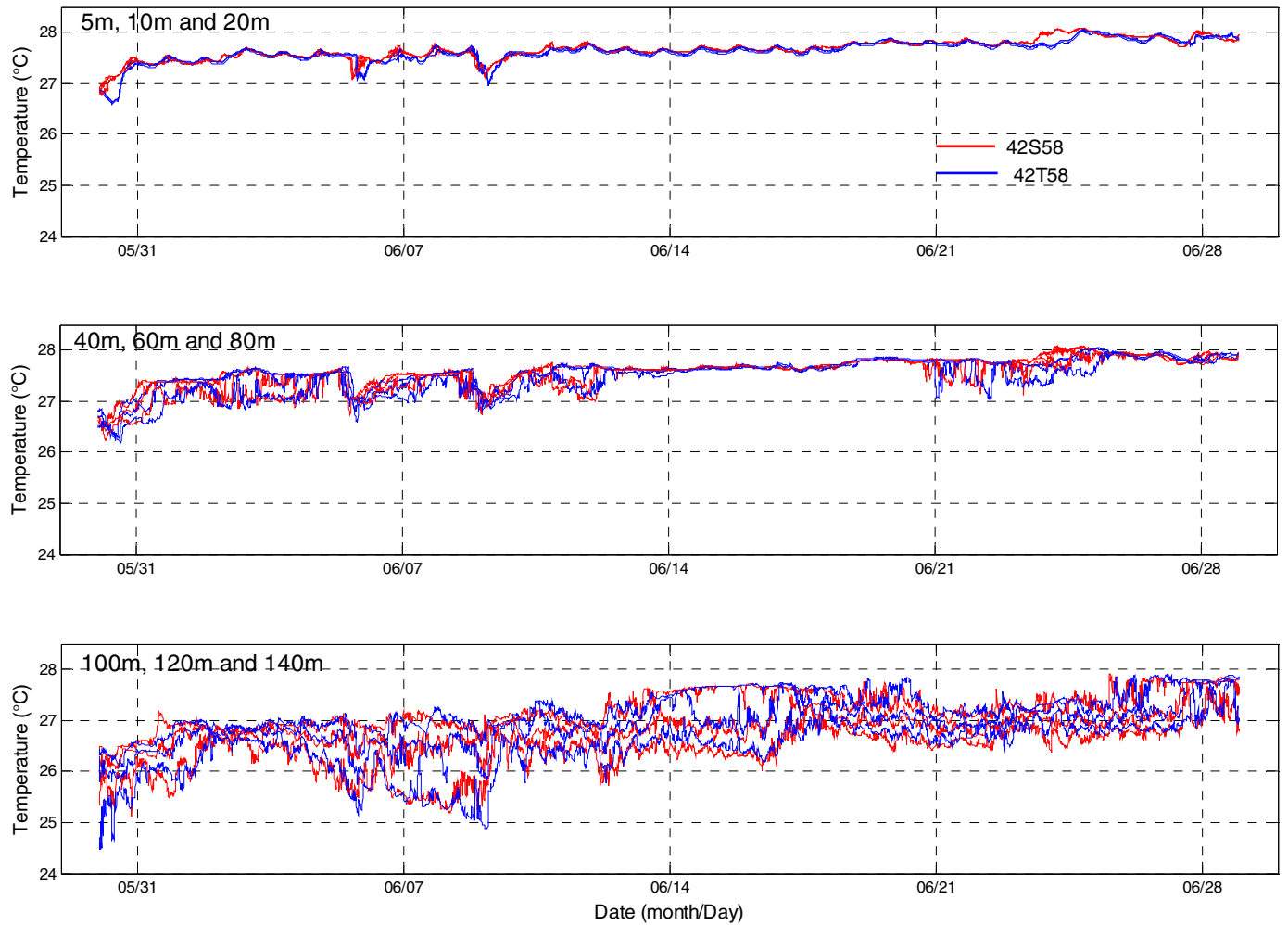

Fig. 5. Time series comparing subsurface temperature observations at station $42 \mathrm{~S} 58$ (red) to station 42T58 (blue
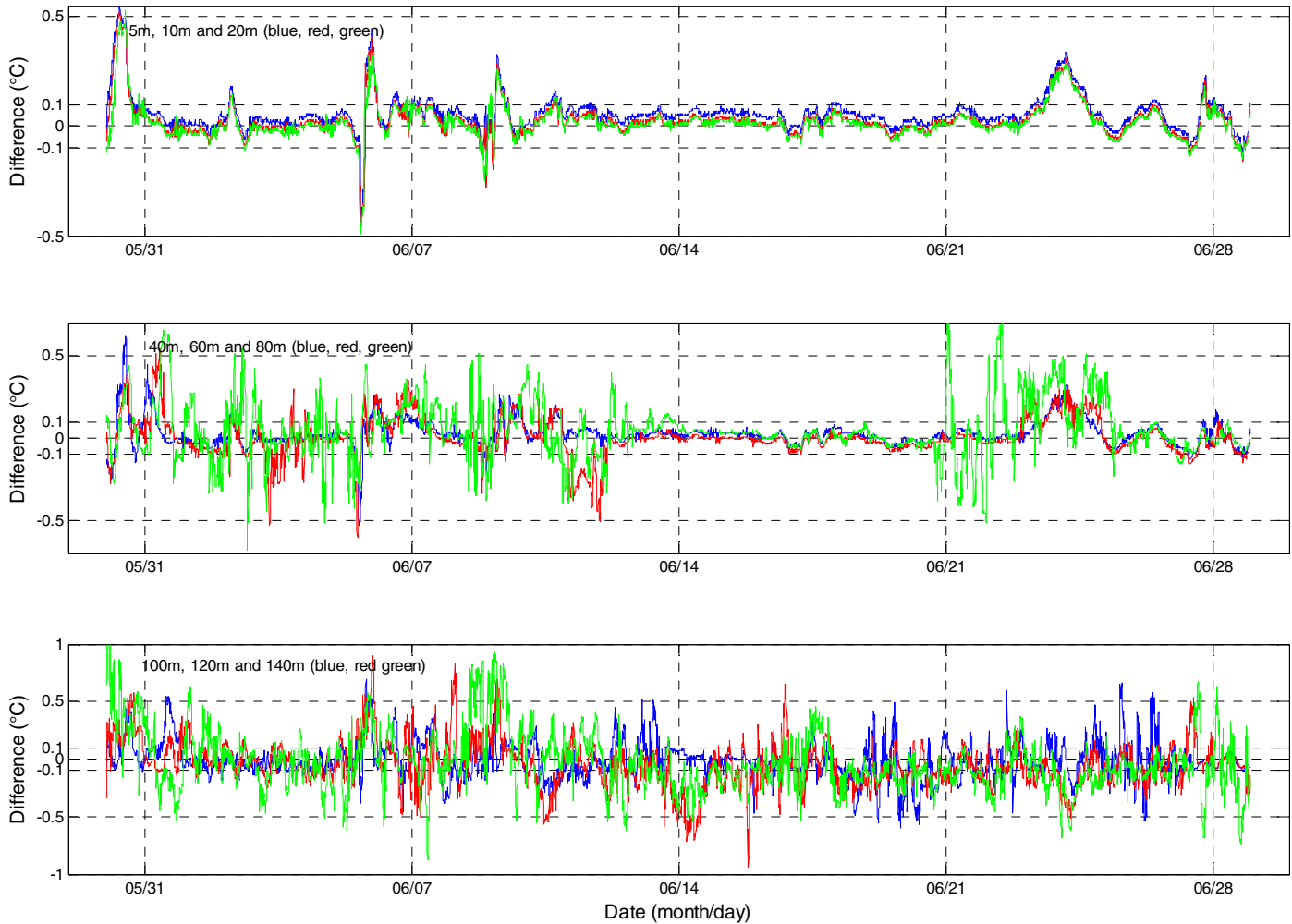

Fig. 6. Time series of difference in subsurface water temperature between stations $42 \mathrm{~S} 58$ and $42 \mathrm{~T} 58$. 
Table 1 Summary statistics comparing temperature performance of thermistor string to SBE inductive sensors.

\begin{tabular}{|c|c|c|c|c|c|c|c|}
\hline Depth (m) & $\pm 1.0^{\circ} \mathrm{C}(\%)$ & $\pm 0.1^{\circ} \mathrm{C}(\%)$ & $\pm 0.01^{\circ} \mathrm{C}(\%)$ & $\begin{array}{l}\text { Thermistor } \\
\text { Mean }\left({ }^{\circ} \mathrm{C}\right)\end{array}$ & Mean Diff $\left({ }^{\circ} \mathrm{C}\right)$ & $\operatorname{MAE}\left({ }^{\circ} \mathrm{C}\right)$ & $\mathbf{R}^{2}$ \\
\hline 5 & 100 & 82.51 & 12.52 & $27.615( \pm 0.21)$ & $0.06( \pm 0.08)$ & 0.07 & 0.844 \\
\hline 10 & 100 & 90.09 & 24.56 & $27.643( \pm 0.21)$ & $0.03( \pm 0.08)$ & 0.05 & 0.846 \\
\hline 20 & 100 & 89.81 & 29.32 & $27.644( \pm 0.22)$ & $0.02( \pm 0.08)$ & 0.05 & 0.863 \\
\hline 40 & 100 & 85.46 & 25.02 & $27.603( \pm 0.26)$ & $0.03( \pm 0.08)$ & 0.06 & 0.894 \\
\hline 60 & 100 & 76.05 & 26.04 & $27.588( \pm 0.30)$ & $0.00( \pm 0.12)$ & 0.08 & 0.847 \\
\hline 80 & 100 & 62.27 & 12.73 & $27.415( \pm 0.36)$ & $0.05( \pm 0.17)$ & 0.12 & 0.781 \\
\hline 100 & 100 & 60.37 & 12.57 & $27.215( \pm 0.38)$ & $-0.01( \pm 0.17)$ & 0.12 & 0.824 \\
\hline 120 & 100 & 44.77 & 6.92 & $26.904( \pm 0.40)$ & $-0.05( \pm 0.20)$ & 0.15 & 0.756 \\
\hline 140 & 99.81 & 36.10 & 5.44 & $26.446( \pm 0.55)$ & $-0.03( \pm 0.26)$ & 0.19 & 0.782 \\
\hline
\end{tabular}

To assist us with evaluating the impact of the temperature errors on a "real-world" application, the ocean heat content was calculated for water $\geq 26^{\circ} \mathrm{C}$, the integrated vertical temperature to the depth of the $26^{\circ} \mathrm{C}$ isotherm is known as the "hurricane heat potential" [10]. To hurricane modelers the heat content is the fuel available to feed an approaching storm. The total heat content of water mass is the amount of heat energy stored there. It can be determined by the formula:

$$
Q=c_{p} \rho \int_{2[T \mathbf{2} \mathbf{W}\}}^{\nabla} \Delta T(x, y, z, t) d z
$$

where $\mathrm{Q}$ is the total heat content $\left(\mathrm{J} \mathrm{m}^{-2}\right), \mathrm{c}_{\mathrm{p}}$ is the specific heat capacity of the seawater at constant pressure $(4178 \mathrm{~J} \cdot \mathrm{kg}-1 \cdot \mathrm{K}$ $-1), \rho$ is the average density of the upper ocean $\left(1026 \mathrm{~kg} \mathrm{~m}^{-3}\right)$, and $\Delta T$ is the temperature difference between the sea surface and the temperature at 140 meters. The depth of $140 \mathrm{~m}$ was chosen for the integration, since it was the transition depth to temperatures less than $26^{\circ} \mathrm{C}$. The choice of a constant depth for the integration of heat content eliminated the influence of a variable seawater volume on these results and instead focused on the impact of temperature differences. The units for hurricane heat potential are given in $\mathrm{kJ} \mathrm{cm}^{-2}\left(=10^{7} \mathrm{~J} \mathrm{~m}^{-2}\right)$.

The distribution of the difference in $\mathrm{OHC}$ between the stations due to measured temperature is shown in Fig. 7. In this figure, all the energy to the right of the dashed line represents an decrease in the hurricane heat potential due to reporting a low temperature value by the thermistor string, whereas to the left of the line is the opposite, excess heat. Overall, the mean difference was $4.6 \mathrm{~kJ} \mathrm{~cm}^{-2}\left( \pm 15 \mathrm{~kJ} \mathrm{~cm}^{-2}\right)$. For locations of tropical cyclones in the Atlantic, $\mathrm{OHC}$ values range up to $150 \mathrm{~kJ} \mathrm{~cm}^{-2}$ with a mean of $41 \mathrm{~kJ} \mathrm{~cm}^{-2}$ [5]. Based on the mean Atlantic $\mathrm{OHC}$ and the mean $\mathrm{OHC}$ difference using thermistor string data, the average error was $11 \%$, but given the high variance in the temperature data could reach up to $47 \%$. The total heat energy for the 29 day period ( 289 $\mathrm{MJ} / \mathrm{cm}^{-2}$ ) calculated from the thermistor string produced an identical error, an $11 \%$ reduction compared to the inductive instruments. Approximately $69 \%$ of the observations produced an underestimation of hurricane heat potential. However, $30 \%$ of the temperature values indicate an overestimation of the heat content, meaning the thermistor string is measuring a higher temperature. The diminishing agreement and sign reversal of mean difference between the stations at depth (Table 1) demonstrate the majority of this $30 \%$ overestimation is occurring below 100 meters, near the $26^{\circ} \mathrm{C}$ isotherm, which in practice would increase the measured depth of the $26^{\circ} \mathrm{C}$ isotherm and create an even larger overestimation.

In either scenario, an overestimation or an underestimation, accurate temperature observations are crucial to $\mathrm{OHC}$ calculations. Particularly in regions with large $\mathrm{OHC}$ values, such as the Gulf of Mexico Loop Current where estimates from satellite-derived observation can differ from in-situ observations by up $15 \%$ [8].

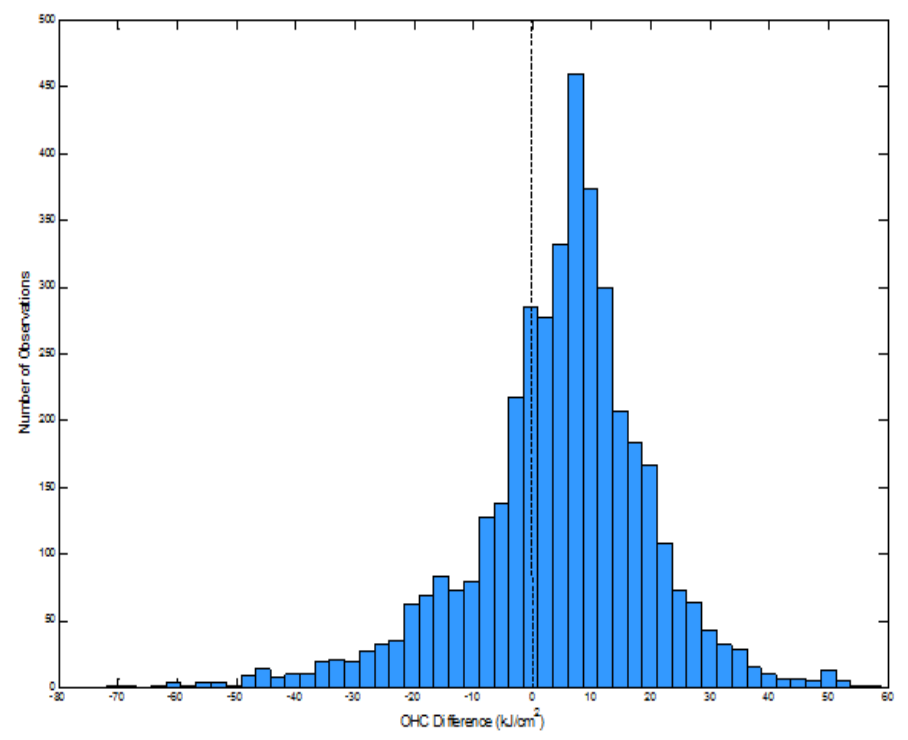

Fig. 7. Distribution of OHC difference from sea-surface to 140 $\mathrm{m}$ (depth of $26^{\circ} \mathrm{C}$ isotherm) between reference station $42 \mathrm{~S} 58$ and thermistor string on station $42 \mathrm{~T} 58$. 


\section{CONCLUSIONS}

In general, the agreement between the Sea-Bird instruments used as reference and the ThermArray thermistor string is within $\pm 0.2^{\circ} \mathrm{C}$. The correlation between the two stations at all depths was greater than 0.75 and above $80 \mathrm{~m}$ the MAE is within $\pm 0.1^{\circ} \mathrm{C}$. However, we do see a larger spread in the thermistor string at depth than compared to the SBE reference sensors. Yet, given the $13 \mathrm{~km}$ separation between the between the mooring, and the deployment location along the northern perimeter of the Caribbean Current, we cannot say with certainty this error is solely the result of the thermistor string.

While it has been shown the thermistor string is acceptable within $\pm 0.1^{\circ} \mathrm{C}$ greater than $80 \%$ of the time in the upper layer $(<80 \mathrm{~m})$, we must use caution when using the observations for derived quantities, such as heat content. The $\mathrm{OHC}$ errors reached as high as $19 \mathrm{~kJ} \mathrm{~cm}^{-2}$, well within the range of the 10$17 \mathrm{~kJ} \mathrm{~cm}^{-2}$ threshold shown to sustain a tropical cyclone [10 and 11]. Lastly, we found the thermistor string difficult to deploy resulting in instrument deployment depth error and the survivability in the marine environment not conducive to hurricane observations.

\section{ACKNOWLEDGMENT}

We are grateful to the team members of the NDBC mooring group for their expert handling of the mooring and the associated instruments. In addition, a special thank you to Richard Burgess, of the NDBC instrumentation lab, your assistance in conducting the lab bench tests was invaluable.

\section{REFERENCES}

[1] Palmen, E., 1948. On the formation and structure of tropical cyclones. Geophysika, 3, 26-38.

[2] Miller, B.I., 1958. On the maximum intensity of hurricanes. J. Meteor., 15, 185-195.

[3] Reynolds, R.W., and T.M. Smith, 1994. Improves global sea surface temperature analyses using optimum interpolation. J. Climate., 7, 929948.

[4] Cione, J.J., and E.W. Uhlhorn, 2003. Sea surface temperature variability in hurricanes: Implication with respect to intensity change. Mon. Wea. Rev., 131, 1783-1796.

[5] Mainelli, M., M. DeMaria, L.K. Shay, and G. Goni, 2008. Application of oceanic heat content estimation to operational forecasting of recent Atlantic category 5 hurricanes. Weather and Forecasting , 23, 3-16.

[6] Andrade, C.A., E.D. Baron, and C.N.K. Mooers, 2003. Evidence for an eastward flow along the Central and South American Caribbean Coast. J. Geophys. Res., 108(C6), doi: 10.1029/2002JC001549

[7] Jury, M, 2011. Long-term variability and trends in the Caribbean Sea. Int'l J. Oceanogr., vol 2011, doi: 10.1155/2011/465810

[8] Laing, A., and J.L. Evans, 2011. Introduction to Tropical Meteorology, $2^{\text {nd }}$ Ed. University Corporation for Atmospheric Research, accessed 28 Sept2015.

http://www.goesr.gov/users/comet/tropical/textbook_2nd_edition/index.htm

[9] Richardson, P.L., 2005. Caribbean current and eddies as observed by surface drifters. Deep Sea Res. Part II, 52, 429-463.

[10] Leipper, D.F., and D. Volgenau, 1972. Hurricane heat potential of the Gulf of Mexico. J. Phys. Oceanogr., 2, 218-224.

[11] Shay, L.K., G.J. Goni, and P.G. Black, 2000. Effects of a warm oceanic feature on Hurricane Opal. Mon. Wea. Rev., 128, 1366-1383 